\title{
A Novel STAT3 Mutation in a Patient with Hyper-lgE Syndrome Diagnosed with a Severe Necrotizing Pulmonary Infection
}

This article was published in the following Dove Press journal: Journal of Asthma and Allergy

\section{Ran Zhao'* \\ Chao Wang ${ }^{1, *}$ \\ Chao Sun' \\ Kun Jiang' \\ Shengnan $\mathrm{Wu}^{2}$ \\ Fen $\operatorname{Pan}^{2}$ \\ Zeyu Zeng' \\ Yijing $\mathrm{Hu}^{\prime}$ \\ Xiaoyan Dong'}

'Department of Respiratory, Shanghai Children's Hospital, Shanghai Jiaotong University, Shanghai, 200062, People's Republic of China; ${ }^{2}$ Clinical Laboratory of Shanghai Children's Hospital, Shanghai jiaotong University, Shanghai, 200062,

People's Republic of China

*These authors contributed equally to this work

\begin{abstract}
Purpose: Autosomal dominant hyper-IgE syndrome (HIES) is a rare primary immune deficiency syndrome caused mainly by mutations in the signal transducer and activator of transcription 3 (STAT3) gene. More information on STAT3 mutations is still needed, and further investigation is warranted. A girl with HIES carrying a novel STAT3 mutation who had no obvious apparent symptoms but presented with a severe necrotizing pulmonary infection is described here. We analysed dynamic changes in blood cells and a series of inflammatory factors in the bronchoalveolar lavage fluid (BALF) before and after each bronchoscopic lavage to relieve her severe pulmonary abscess.
\end{abstract}

Patients and Methods: Whole-exome sequencing and Sanger sequencing were used to identify novel STAT3 mutations. Flow cytometry was used for immune analysis of Th17 cells and inflammatory cytokines.

Results: A novel de novo mutation in STAT3 (c.1552C $>$ T, p.Arg518*) was identified in this patient. The number of eosinophils decreased after each bronchoscopy procedure. Elevated interleukin (IL)-8 and IL-1 $\beta$ levels were detected in her right lung BALF in the acute phase, but they were reduced after four bronchoscopic lavage procedures and the administration of antimicrobial medicine.

Conclusion: More information on STAT3 mutations is needed to investigate the relationship between the genotype and HIES phenotype. Bronchoscopic lavages are recommended instead of surgery to relieve acute severe pulmonary abscesses and necrotizing pulmonary infections in paediatric patients with HIES.

Keywords: hyper-IgE syndrome, infection, lung alveolar lavage fluid, pulmonary infection

\section{Introduction}

Hyper-IgE syndrome (HIES) is a rare primary immune deficiency syndrome. Patients exhibit obviously elevated serum IgE levels, eczematous dermatitis, and recurrent skin and pulmonary infections, along with several nonimmune features. Most cases are sporadic, but autosomal recessive (AR) and autosomal dominant (AD) cases have been described. ${ }^{1}$ Mutations in signal transducer and activator of transcription 3 (STAT3) can result in autosomal dominant HIES.

STAT3 is a transcription factor involved in transducing the signals from numerous cytokines, most notably interleukin (IL)-6, IL-10, IL-11, IL-21, and leptin. ${ }^{1,2}$ Thus, STAT3 mutations result in the deregulation of TGF- $\beta$, IL-6, or IL-21 signalling, which are required for naive CD4+ T cells to switch to Th17 cells. ${ }^{3-5}$ As a result, the differentiation of Th17 cells is impaired, and the level of IgE is
Correspondence: Xiaoyan Dong Department of Respiratory, Shanghai Children's Hospital, Shanghai Jiaotong University, No. 355 Luding Road,

Shanghai, 200062, People's Republic of China

Email dongxy@shchildren.com.cn
Journal of Asthma and Allergy 2021:14 219-227 
increased. ${ }^{6}$ To date, approximately one hundred individual STAT3 mutations have been reported. ${ }^{7,8}$ STAT3 influences other downstream signalling pathways, ${ }^{9,10}$ which leads to other features of HIES involving the joints, cranial synostosis and other symptoms.

HIES is difficult to diagnose. The incidence of HIES is less than $0.001 \%$, and not all patients show obvious features. As a result, doctors confuse HIES with common pulmonary infections. HIES is also difficult to confirm. ${ }^{11}$ Pathology and genotype information is still incomplete for these patients, ${ }^{12}$ and the corresponding relationships between genotypes and phonotypes are not entirely clear. Currently, a scoring system devised by the NIH that combines STAT3 mutations and decreased Th17 numbers has been used to help diagnose AD-HIES. The treatment of this syndrome is complex. Patients with HIES experience recurrent infections with pathogenic microorganisms and even have a risk of tumorigenesis, ${ }^{13}$ but no permanent cure or targeted treatment is currently available for them. ${ }^{2}$ Therefore, related studies are still necessary for HIES.

\section{Case Report}

The patient was a 10-year-old girl who suffered from upper respiratory tract infections 4 to 5 times a year. Over her lifetime, she was diagnosed with pneumonia three times. This time, she was admitted to our hospital due to severe pneumonia accompanied by abscesses and pulmonary cysts.

The blood analysis showed a high level of C-reactive protein at $53 \mathrm{mg} / \mathrm{L}$ (reference range: $<5 \mathrm{mg} / \mathrm{L}$ ) and an obviously increased eosinophil count of $4.91 \times 10^{9}$ cells/ $\mathrm{L}$ (reference range: $0.05-0.5 \times 10^{9}$ cells $/ \mathrm{L}$ ). The immunological assessment showed an elevated $\mathrm{IgE}$ level of $11,300 \mathrm{IU} / \mathrm{mL}$ (reference range: $<200 \mathrm{IU} / \mathrm{mL}$ ), increased B cell count (CD19+) of 35.010\% (reference range: 14.35-22.65\%), and decreased Th17 cell count of 3.08\% (reference range: $7.13-$ $24.53 \%$ ). The expression of the cytokines IL-5, IL-6, IL-2, IL-1 $\beta$, IL- 8 and TNF- $\alpha$ was obviously increased (Table 1). According to the results of the CT scan, segmental consolidation with cavity formation was observed in the upper and lower lobes of the right lung, while bronchodilation was observed in the left lung (Figure 1). Tracheal microscopy showed a large amount of white, thick secretions and phlegm plugs in the bronchiole, and she had bronchiolitis obliterans with bronchiectasis (Figure 2A and B show the first tracheal microscopy image).

After scoring the patient using a clinical scoring system (NIH HIES) developed to screen members of known AD-
HIES kindreds, a score of 30 points was recorded for this patient (Table 2), who was suspected as having HIES. The scoring system was established by the NIH group who recognized STAT3-HIES, ${ }^{14}$ and is currently commonly used to evaluate patients with sporadic cases. According to the guidelines developed by Woellner et $\mathrm{al}^{11}$ we performed whole-exome sequencing, and the results revealed a de novo nonsense mutation in STAT3 that was combined with a decrease in the number of Th17 cells, and we confirmed that the patient had AD-HIES.

During her hospitalization, linezolid and itraconazole were used as anti-infection treatments, thymalfasin was used for immune regulation, and acetylcysteine was used for sputum reduction. Four tracheal endoscopic lavage procedures were conducted to help relieve the severe pulmonary abscess. We provide systemic information on blood cell percentages and immune cytokine concentrations in the bronchoalveolar lavage fluid (BALF) before and after lavage in this study (Tables 3 and 4). At the time of discharge, chest $\mathrm{CT}$ imaging showed an improvement of her pulmonary symptoms, and most blood cell counts in this patient had returned to normal; however, the percentage of eosinophils was still elevated, and the cytokines in the BALF of the right lung were still high but had decreased to normal 15 days later at follow-up. We informed the parents that the treatment of this child would be long-term and ongoing, and genetic counselling was suggested.

\section{HIES Scores}

A score of thirty was obtained using the NIH scoring system (Table 2). This patient showed no obvious changes in appearance, such as skin abscesses, retained primary teeth, scoliosis, characteristic face, hyperextensibility and increased nasal width, which made the diagnosis difficult.

The IgE level in this patient was extremely high and reached $11,300 \mathrm{IU} / \mathrm{mL}$ (10 points). The eosinophil count was greater than $4.91 \times 10^{9}$ cells/L (6 points). During her 10 years of life, she was diagnosed with pneumonia 3 times (6 points). Upper respiratory infections occurred 4-5 times per year (2 points), and her lungs showed typical bronchiectasis (6 points). All these symptoms resulted in a suspicion of HIES. In this situation, we performed genetic analysis using whole-exome sequencing and a flow cytometric analysis of Th17 cell counts. 
Table I Basic Laboratory Work-Up of a Female Patient with AD-HIES

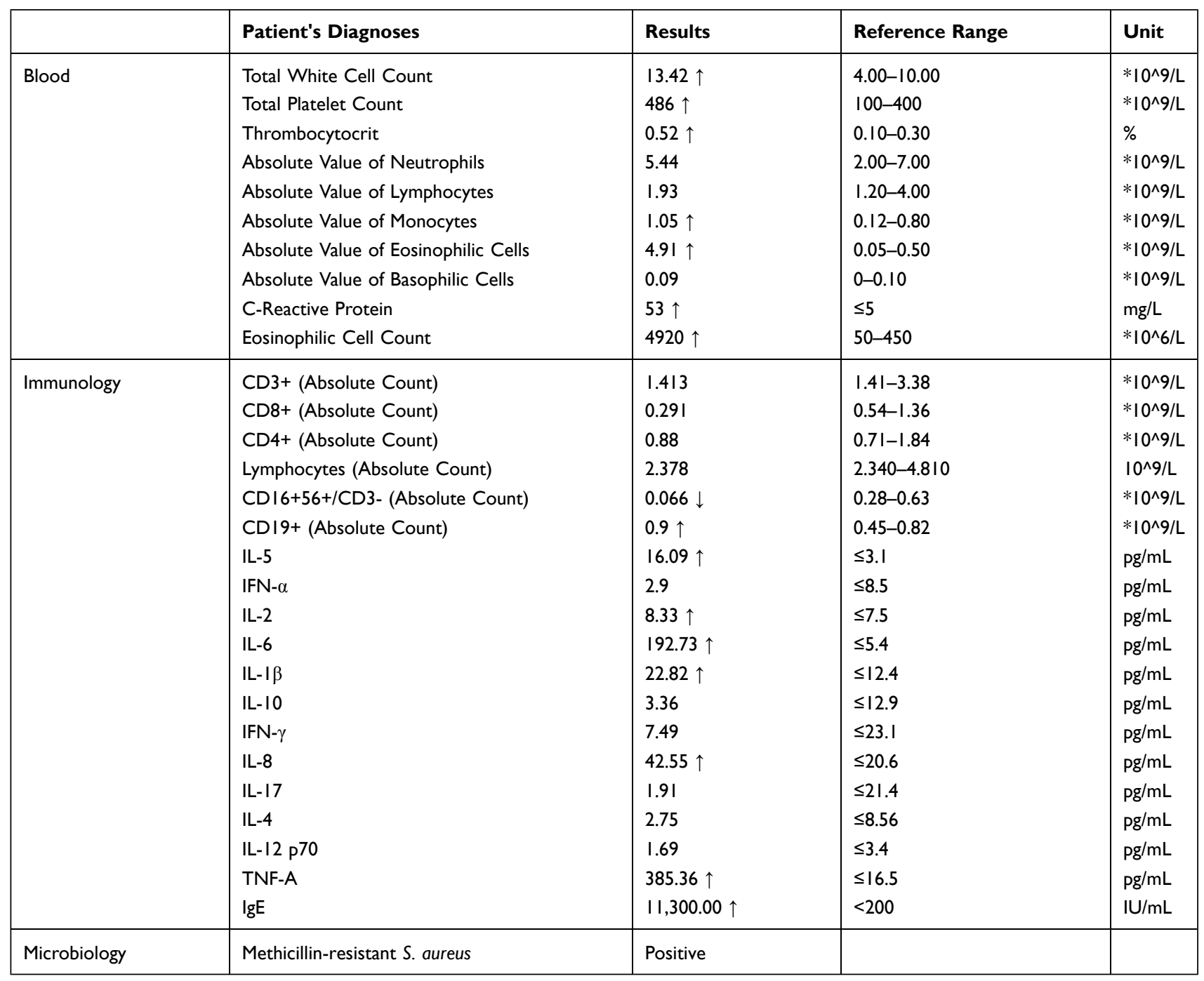

Notes: $\uparrow$, Increase; $\downarrow$, decrease.

\section{Identification of a Novel STAT3 Mutation}

Sequencing of STAT3 revealed a novel, de novo, heterozygous c. $1552 \mathrm{C}>\mathrm{T}$ mutation (Figure $3 \mathrm{~A}$ ). This mutation is a nonsense variant (p.Arg518*) that might result in premature truncation of the peptide in the DNA binding domain. Both parents had wild-type genotypes (Figure 3B). Approximately one hundred individual STAT3 mutations spanning most domains of this protein, except the coiled coil domain, with supporting clinical phenotypes, have been reported to lead to AD-HIES. ${ }^{8}$ STAT3 is a transcription factor involved in transduction of signals from IL-6, an inflammatory cytokine that is crucial for Th17 differentiation. ${ }^{15}$

\section{ThI7 Cell Detection}

We conducted a flow cytometric analysis of Th1, Th2, and Th17 cells. CD45/SSC gating was used to select all leukocytes, CD3+/CD4+ gating was used to choose $\mathrm{T}$ helper cells (data not shown), and CD183/CD196 gating was used for the analysis of Th1, Th2, and Th17 cells (Figure 3C). CD183+CD196+ represents Th1 cells, CD196+CD183- represents Th17 cells, CD196-CD183+ represents Th1 cells. Both the number and ratio (the absolute number of Th17 cells divided by CD4 $+\mathrm{T}$ cells) of Th17 cells decreased, and the ratios (the absolute number of Th1 and Th2 cells divided by CD4+ T cells) of Th1 cells and Th2 cells decreased, according to the reference range (Table 5). Th2 cells increased the number of $B$ cells and subsequently increased the $\operatorname{IgE}$ level. The aberrant mutation of STAT3 resulted in abnormal IL-6 levels (Table 1) and a reduction in the number of Th17 cells. 

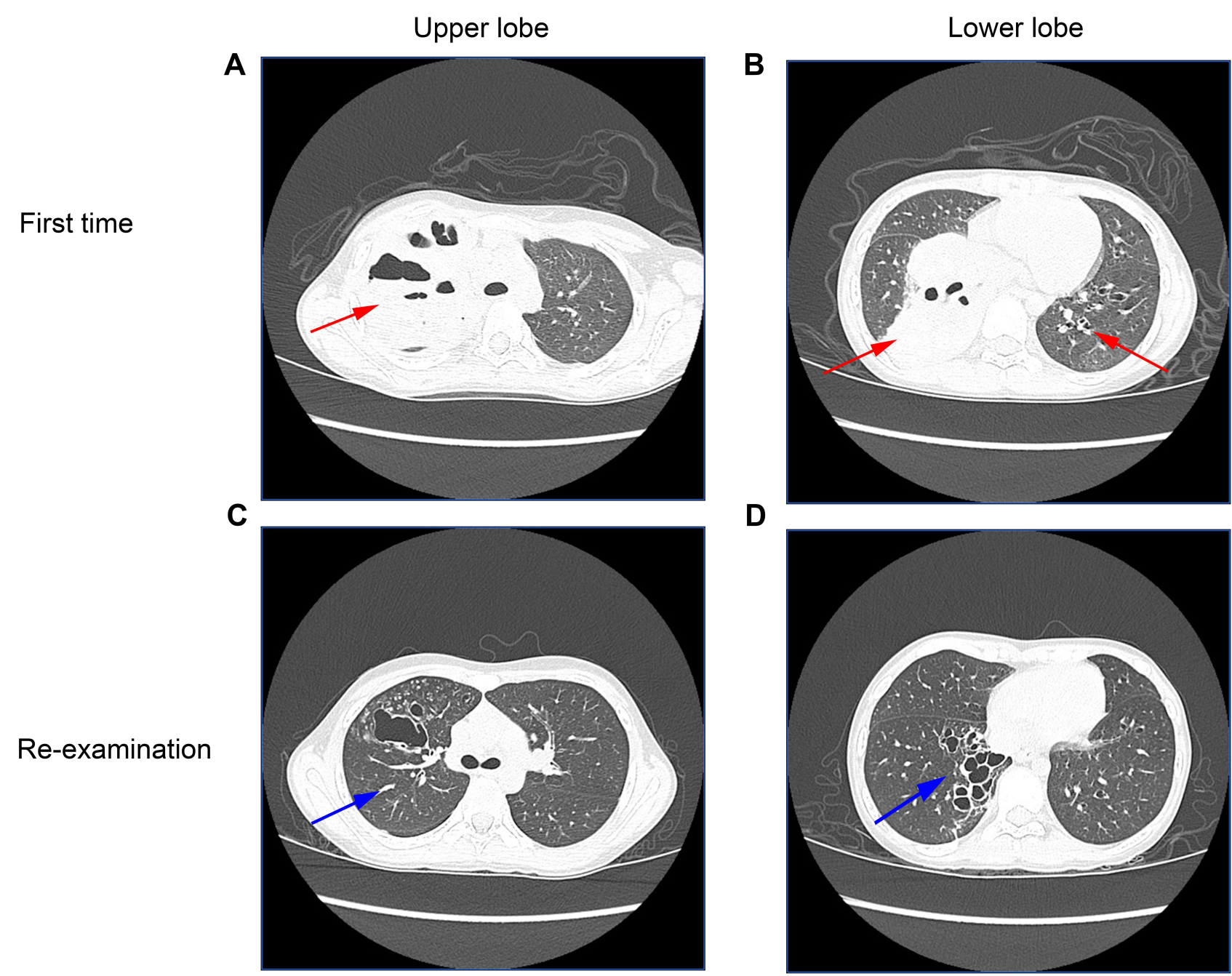

D

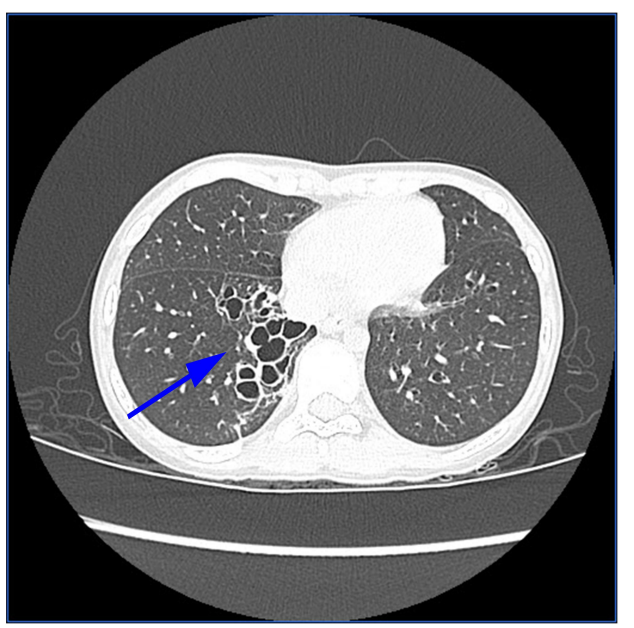

Figure I Pulmonary imaging by CT scan before and after treatment.

Notes: (A and B) The patient had numerous enhanced solid lesions and cavities in the upper and lower lobes of the right lung (red arrows in the left panels). Bronchiectasis was observed in the left lung (red arrow in the right panels). (C and D) After four bronchoscopic lavage procedures combined with antimicrobial medicine treatments, the patient was examined again after 15 days. The abscesses were eliminated and absorbed compared to the acute infection phase, and cavities remained (blue arrows).

\section{Bronchoscopic Lavage}

A large area of lesions was observed in both the upper and lower lobes of the right lung; bronchiectasis was indicated in the left lung. We conducted bronchoscopic lavage 4 times to help relieve her symptoms. We provide the dynamic changes in the levels of the series of inflammatory factors in BALF and blood cells before and after bronchoscopy. BALF samples were collected from patient when she was undergoing diagnostic bronchoscopy, BAL was performed using flexible bronchofibrescopy after anaesthesia with lidocaine, sterile saline was instilled into the right and left lobes of the lung, and BALF samples were collected in sterile containers.

After 4 bronchoscopic lavages combined with antimicrobial intake, most blood cell counts returned to normal.
Although the neutrophil percentage was still lower than normal and the eosinophil percentage was still elevated, the eosinophil count decreased immediately after each bronchoscopic lavage (Table 3). Because the patient had a large and severe lesion in her right lung, the levels of the inflammatory factors IL- 8 and IL-1 were higher in the right lung BALF, while the levels in the left lung BALF were mostly normal. The patient was re-examined half a month later by performing another tracheal lavage (Figure 2C and D showed this time of bronchoscope), and the indicators in lavage fluid from the left and right lungs were mostly normal. We provide a tracheal image of the right lung (Figure 2) and a CT scan of the lung, showing no further expansion of the lung lesions and alleviation of the pulmonary abscess (Figure 1C and D). 
A

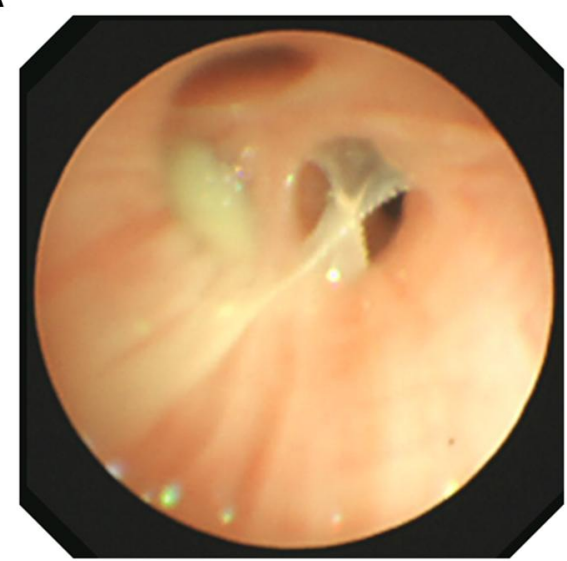

C

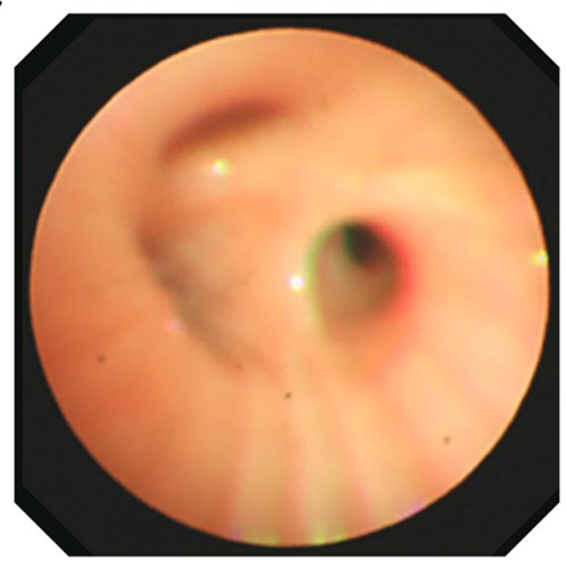

B

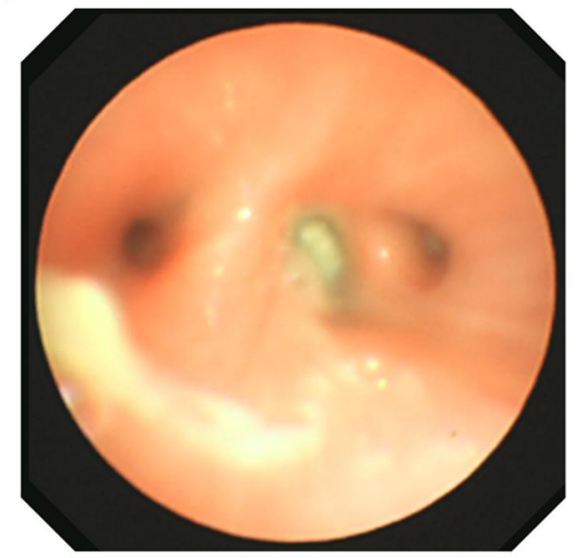

D

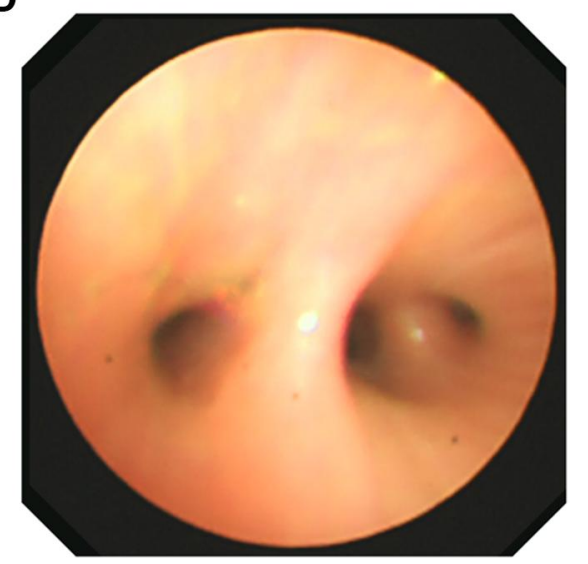

Figure 2 (A) Tracheal microscopy image of the right upper lobe at the first time of bronchoscope. (B) The tracheal microscopy image of the right middle lower lobe at the first time of bronchoscope. (C and D) Tracheal microscopy images were captured at same location, (C) for the right upper lobe and (D) for the right middle lower lobe, when the patient was re-examined half a month later, after four bronchoscope procedures and antibiotic treatments.

\section{Discussion}

In this patient, the apparent symptoms of HIES, such as bone and primary teeth abnormalities, and the characteristic face, were not obvious, but severe pulmonary inflammation symptoms, such as pulmonary abscess, bronchiolitis obliterans, pulmonary consolidation, bronchiectasis, and methicillin-resistant Staphylococcus aureus infection, were present. Thus, her characteristics might be confused with those of patients with common pneumonia. The methicillin-resistant $S$. aureus infection alerted us, because the recurrence of infections with antibioticresistant strains is frequently observed in patients with an immune deficiency. Based on her high concentration of IgE and increased number of eosinophils, we performed a genetic analysis and FACS analysis of her $\mathrm{T}$ cells. A novel mutation in STAT3 and decreased numbers of Th17 cells were detected. This patient had a score of 30 according to the HIES NIH scoring system. All symptoms confirmed a diagnosis of HIES. ${ }^{1}$ Patients with AD-HIES are clinically characterized by an increased susceptibility to infection with $S$. aureus, ${ }^{16}$ and the colonizing $S$. aureus strains are mainly antibiotic-resistant strains that harbour key virulence factors. ${ }^{17}$ Therefore, when a patient has severe recurrent pneumonia more than 3 times, an infection with antibiotic-resistant $S$. aureus, an IgE level higher than $2000 \mathrm{IU} / \mathrm{mL}$ and elevated numbers of eosinophilic cells greater than $800 / \mu \mathrm{L}$, HIES should be considered, and scoring and genetic and Th cell analyses are recommended. Her CRP level was elevated, combined with a pulmonary infection, which is uncommon for patients with AD-HIES.

A novel nonsense mutation in the DNA binding domain of STAT3 was identified in this patient, resulting in protein dysfunction. This nonsense mutation causes premature truncation of the peptide chain during synthesis. To date, approximately 100 genetic mutations in STAT3 
Table 2 Scoring of This Patient According to the NIH HIES Scoring System

\begin{tabular}{|c|c|c|c|c|}
\hline \multirow[t]{2}{*}{ Clinical Findings } & \multicolumn{4}{|l|}{ Points } \\
\hline & 0 & 2 & 6 & 10 \\
\hline $\begin{array}{l}\text { Highest serum lgE } \\
\text { level }(\mathrm{IU} / \mathrm{mL})^{\mathrm{a}}\end{array}$ & $<200$ & & & $\begin{array}{l}>2000 \\
\text { (yes) }\end{array}$ \\
\hline $\begin{array}{l}\text { Pneumonia (episodes } \\
\text { over lifetime) }\end{array}$ & None & I & 3 (yes) & \\
\hline $\begin{array}{l}\text { Parenchymal lung } \\
\text { anomalies }\end{array}$ & Absent & & $\begin{array}{l}\text { Bronchiectasis } \\
\text { (yes) }\end{array}$ & \\
\hline $\begin{array}{l}\text { Highest eosinophil } \\
\text { count (cells } / \mu \mathrm{L})^{\mathrm{b}}\end{array}$ & $<700$ & & $>800$ (yes) & \\
\hline $\begin{array}{l}\text { Number of upper } \\
\text { respiratory infections } \\
\text { per year }\end{array}$ & $\mathrm{I}-2$ & $\begin{array}{l}4-6 \\
\text { (yes) }\end{array}$ & & \\
\hline
\end{tabular}

Notes: ${ }^{a}$ Normal level $<130 \mathrm{lU} / \mathrm{mL}$. ${ }^{\mathrm{b}}$ Reference range: $0.05-0.5 \times 10^{9}$ cells/L.

have been identified in domains other than the DNA binding domain, such as the $\mathrm{SH} 2$ domain, linker domain, transactivation domain and $\mathrm{N}$-terminal domain. In mouse keratinocytes, STAT3 deletion results in eczema-like inflammation and a marked elevation in IgE levels. ${ }^{18}$ Unfortunately, the correlation between genotype and phenotype has not been completely established in patients with AD-HIES. ${ }^{11,19}$ Nonimmune features are enriched in patients with $\mathrm{SH} 2$ domain mutations, ${ }^{20}$ and patients with malignancies also express a mutant in this domain. ${ }^{21}$ Our patient showed no obvious apparent symptoms. The mutation type and location of the STAT3 mutation in this patient were unable to be predicted from her clinical presentation, because the genotype-phenotype correlations in patients with AD-HIES are poor and remain to be discovered. More gene mutations and phenotypes should be analysed to determine the corresponding relationship. Thus, more genetic data and analyses are still needed for a diagnosis of this disease.

This patient had no classic physical stigmata, but she presented severe pulmonary symptoms. A large area of lesions was observed in both the upper and lower lobes of the right lung; bronchiectasis was indicated in the left lung. Surgical removal was not advised for this child when considering her quality of life in the future; however, medicine intake alone did not alleviate her poor condition. Thus, we conducted bronchoscopic lavage 4 times to help relieve her poor symptoms. As shown in our CT and tracheal images, after physical removal of phlegm combined with antiinflammatory medicine treatment, the pulmonary symptoms were relieved. We show the dynamic changes in the levels of a series of inflammatory factors in BALF and blood cells before and after bronchoscopy. The BALF information might present the pulmonary condition more directly. IL-8 levels were high in the right

Table 3 Dynamic Analysis of Changes in Blood Cell Counts Before and After Four Bronchoscopic Lavages

\begin{tabular}{|c|c|c|c|c|c|c|c|c|c|}
\hline Content & Before I & After I & Before 2 & After 2 & Before 3 & After 3 & Before 4 & After 4 & Reference Range \\
\hline Total White Cell Count & $12.36 \uparrow$ & $11.77 \uparrow$ & $10.90 \uparrow$ & 8.84 & 8.71 & $13.84 \uparrow$ & 9.37 & 8.07 & $4.00-10.00 * 10^{\wedge 9}$ cells $/ \mathrm{L}$ \\
\hline Total Platelet Count & $587.00 \uparrow$ & $625.00 \uparrow$ & $459.00 \uparrow$ & 362.00 & 171.00 & 294.00 & 288.00 & 307.00 & $100.00-400.00 * 10^{\wedge 9}$ cells $/ L$ \\
\hline $\begin{array}{l}\text { Neutrophil Percentage of } \\
\text { Total White Cells }\end{array}$ & $41.20 \downarrow$ & $78.30 \uparrow$ & $42.10 \downarrow$ & $30.60 \downarrow$ & 54.70 & 60.00 & $28.00 \downarrow$ & $47.70 \downarrow$ & $50.00-70.00 \%$ \\
\hline $\begin{array}{l}\text { Lymphocyte Percentage of } \\
\text { Total White Cells }\end{array}$ & $20.10 \downarrow$ & $13.80 \downarrow$ & $23.00 \downarrow$ & $52.10 \uparrow$ & $21.20 \downarrow$ & $29.80 \downarrow$ & 40.00 & 31.40 & $30.00-40.00 \%$ \\
\hline $\begin{array}{l}\text { Eosinophilic Cell Percentage } \\
\text { of Total White Cells }\end{array}$ & $32.80 \uparrow$ & $6.90 \uparrow$ & $27.50 \uparrow$ & $5.90 \uparrow$ & $17.80 \uparrow$ & 3.30 & $25.00 \uparrow$ & $12.60 \uparrow$ & $0.50-5.00 \%$ \\
\hline $\begin{array}{l}\text { Monocyte Percentage of } \\
\text { Total White Cells }\end{array}$ & 5.30 & $0.60 \downarrow$ & 5.90 & $10.50 \uparrow$ & 6.10 & 6.60 & 7.00 & 7.90 & $3.00-8.00 \%$ \\
\hline $\begin{array}{l}\text { Basophilic Cell Percentage of } \\
\text { Total White Cells }\end{array}$ & 0.60 & 0.40 & $1.50 \uparrow$ & 0.90 & 0.20 & 0.10 & 0.00 & 0.40 & $0-1.00 \%$ \\
\hline $\begin{array}{l}\text { Eosinophilic Cell Count } \\
\text { C-Reactive Protein }\end{array}$ & $\begin{array}{l}4000.00 \uparrow \\
31.00 \uparrow\end{array}$ & $\begin{array}{l}800.00 \uparrow \\
5.00 \uparrow\end{array}$ & $\begin{array}{l}3000.00 \uparrow \\
\leq 5\end{array}$ & $\begin{array}{l}500.00 \uparrow \\
\leq 5\end{array}$ & $\begin{array}{l}1540.00 \uparrow \\
\leq 5\end{array}$ & $\begin{array}{l}460.00 \uparrow \\
\leq 5\end{array}$ & $\begin{array}{l}2300.00 \uparrow \\
12 \uparrow\end{array}$ & $\begin{array}{l}1020.00 \uparrow \\
\leq 5\end{array}$ & $\begin{array}{l}50.00-450.00 * 10^{\wedge} 6 \text { cells } / \mathrm{L} \\
\leq 5 \mathrm{mg} / \mathrm{L}\end{array}$ \\
\hline
\end{tabular}

Notes: $\uparrow$, Increase; $\downarrow$, decrease. 
Table 4 Dynamic Analysis of Changes in Inflammatory Cytokine Levels in BALF Before and After Four Bronchoscopic Lavages

\begin{tabular}{|l|l|l|l|l|l|l|l|l|l|l|l|}
\hline Content & $\begin{array}{l}\text { Right } \\
\text { BALFI }\end{array}$ & $\begin{array}{l}\text { Left } \\
\text { BALFI }\end{array}$ & $\begin{array}{l}\text { Right } \\
\text { BALF2 }\end{array}$ & $\begin{array}{l}\text { Left } \\
\text { BALF2 }\end{array}$ & $\begin{array}{l}\text { Right } \\
\text { BALF3 }\end{array}$ & $\begin{array}{l}\text { Left } \\
\text { BALF3 }\end{array}$ & $\begin{array}{l}\text { Right } \\
\text { BALF4 }\end{array}$ & $\begin{array}{l}\text { Left } \\
\text { BALF4 }\end{array}$ & $\begin{array}{l}\text { Right } \\
\text { BALF5 }\end{array}$ & $\begin{array}{l}\text { Left } \\
\text { BALF5 }\end{array}$ & $\begin{array}{l}\text { Reference } \\
\text { Range }\end{array}$ \\
\hline IL-8 & 650.34 & 13.24 & $6723.30 \uparrow$ & 80.27 & $1478.78 \uparrow$ & 92 & $2095.98 \uparrow$ & 146.5 & 183.17 & 248.54 & $<666.4 \mathrm{pg} / \mathrm{mL}$ \\
\hline IL-I $\beta$ & $23.22 \uparrow$ & 0.1 & $454.64 \uparrow$ & 0.1 & $1021.11 \uparrow$ & 0.1 & $867.82 \uparrow$ & 0.1 & 11.77 & 0.1 & $<12.07 \mathrm{pg} / \mathrm{mL}$ \\
\hline IL-2 & 0.1 & 0.1 & 0.1 & 0.1 & 0.1 & 0.1 & 0.1 & 0.1 & 0.1 & 0.1 & $<14.95 \mathrm{pg} / \mathrm{mL}$ \\
\hline IL-6 & 0.1 & 0.1 & 0.1 & 0.1 & 0.1 & 0.1 & 0.1 & 0.1 & 0.1 & 0.1 & $<12.7 \mathrm{pg} / \mathrm{mL}$ \\
\hline IL-10 & 0.1 & 0.1 & 0.1 & 0.1 & 0.1 & 0.1 & 0.1 & 0.1 & 0.1 & 0.1 & $<30.25 \mathrm{pg} / \mathrm{mL}$ \\
\hline IL-4 & 0.1 & 0.1 & 0.1 & 0.1 & 0.1 & 0.1 & 0.1 & 0.1 & 0.1 & 0.1 & $<58.44 \mathrm{pg} / \mathrm{mL}$ \\
\hline TNF- $\alpha$ & 0.1 & 0.1 & 0.1 & 0.1 & 0.1 & 0.1 & 0.1 & 0.1 & 0.1 & 0.1 & $<66.00 \mathrm{pg} / \mathrm{mL}$ \\
\hline
\end{tabular}

Notes: BALFI, BALF2, BALF3, and BALF4 represent the BALF samples collected before and after bronchoscopic lavage treatments during the patient's acute phase in the hospital. The reference range referred to the reference range in blood samples from normal people. BALF5: BALF-related results obtained before and after bronchoscopic lavage treatments when the patient was analysed again 15 days later. $\uparrow$, Increase; $\downarrow$, decrease.

BALF and have been reported to play a significant role in IgE-mediated lung inflammation, ${ }^{22}$ while serum IL-6 levels were high.

Currently, a radical treatment is unavailable for this disease, and only symptomatic treatments are used; the effect of gene therapy and omalizumab treatment is still unclear. Given the severity of the patient's illness, she will need to be closely monitored for the best clinical outcomes. Moreover, the child's mental health should also be considered, and psychological counselling was suggested. This disease may also cause tumours in later life stages and has a dominant inheritance pattern; therefore, genetic counselling should be provided. ${ }^{13}$

\section{Conclusion}

To summarize, we report a patient with AD-HIES who carries a novel heterozygous STAT3 mutation. Our patient had no obvious apparent symptoms, except high IgE levels, elevated eosinophil counts, and repeated pneumonia episodes. The diagnosis and treatment of HIES are still complex and difficult, identifying HIESrelated genetic mutations is still necessary, and further analyses of the correlations between different mutations
B

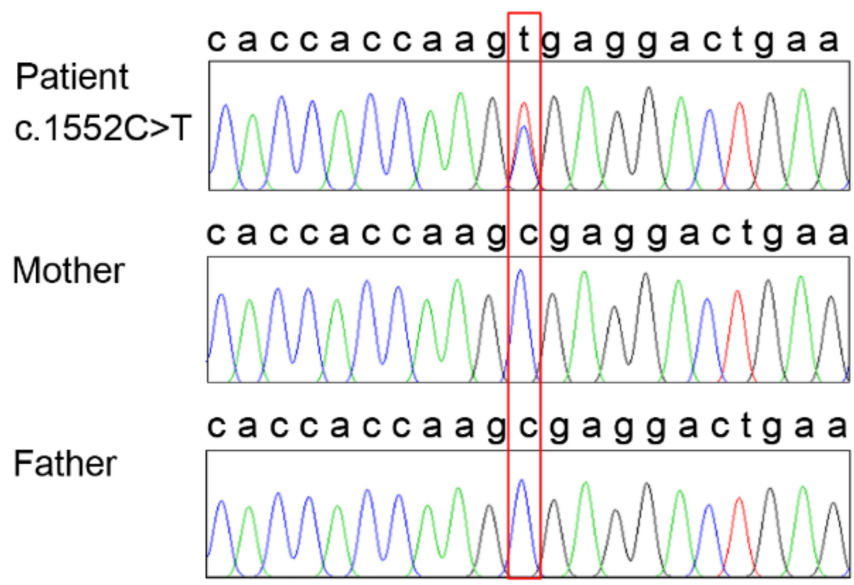

C

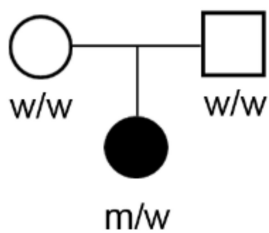

c. $1552 \mathrm{C}>\mathrm{T}$

p. $\operatorname{Arg} 518^{*}$

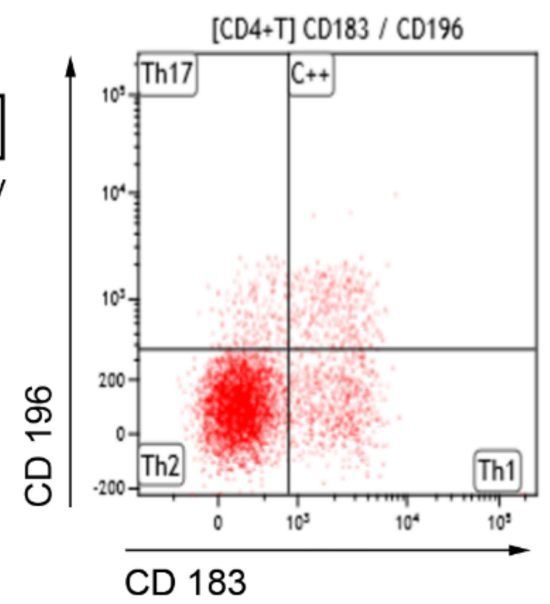

Figure 3 A de novo mutation in STAT3 and decreased number of ThI7 cells were detected.

Notes: (A and B) Targeted Sanger sequencing revealed a STAT3 mutation, (C) 1552C>T (leading to p.Arg645*), in the patient that was not present in her parents. (C) Flow cytometric analysis of ThI7 cells in the patient. CD45/SSC gating was used to select all leukocytes, CD3+/CD4+ gating was used to choose T helper cells, and CDI83/ CDI96 gating was used for the analysis of ThI, Th2, and ThI7 cells. CDI83+CDI96+ represents ThI cells, CDI96+CDI83- represents ThI7 cells, and CDI96-CDI83+ represents ThI cells. 
Table 5 Analysis of the Serum T Helper Cell Counts in This Patient

\begin{tabular}{|l|l|l|}
\hline T Helper Cell Type & Number & Reference Range \\
\hline ThI7 & $27.09 \downarrow$ & $69.1 \mathrm{I}-1 \mathrm{I} 2.8 \mathrm{cells} / \mu \mathrm{L}$ \\
\hline ThI & 108.34 & $89.88-140.7 \mathrm{cells} / \mu \mathrm{L}$ \\
\hline Th2 & 693.08 & $101.7-738.0 \mathrm{cells} / \mu \mathrm{L}$ \\
\hline $\begin{array}{l}\text { Percentages of different } \\
\text { T helper cells among the } \\
\text { total CD4+ T cells }\end{array}$ & Ratio & Reference range \\
\hline ThI7/CD4+ T cells & $3.08 \downarrow$ & $7.13-24.53 \%$ \\
\hline ThI/CD4+ T cells & $12.32 \downarrow$ & $12.65-36.24 \%$ \\
\hline Th2/CD4+ T cells & $78.8 \uparrow$ & $22.38-60.19 \%$ \\
\hline
\end{tabular}

Notes: $\uparrow$, Increase; $\downarrow$, decrease.

and different phenotypes should be performed. Bronchoscopic lavage is suggested instead of surgical removal of lesions for relieving acute pulmonary abscess and inflammation in paediatric patients, and psychological and genetic counselling should be suggested according to the patient's condition.

\section{Consent for Publication}

We have obtained consent from the patient's parents (the patient is less than 18 years old) for the publication of the case report. The study was approved by the Shanghai Children's Hospital, Institutional Review Board, and in accordance with the Declaration of Helsinki.

\section{Acknowledgments}

We would like to thank the patient and her family for their cooperation. We are also grateful to the medical staff who cared for the patient and the laboratory staff at the Department of Genetics, Shanghai Children's Hospital, for their excellent experimental support.

\section{Funding}

This study was supported by the Fund of Shanghai International Science and Technology Cooperation Project (18410721300) and Medical-Engineering Cross Project of Shanghai Jiao Tong University (YG2017MS34).

\section{Disclosure}

The authors report no conflicts of interest in this work.

\section{References}

1. Al-Shaikhly T, Ochs HD. Hyper IgE syndromes: clinical and molecular characteristics. Immunol Cell Biol. 2019;97(4):368-379. doi:10.1111/imcb.12209

2. Sundin M, Tesi B, Sund Bohme M, et al. Novel STAT3 mutation causing hyper-IgE syndrome: studies of the clinical course and immunopathology. $J$ Clin Immunol. 2014;34(4):469-477. doi:10.1007/s10875-014-0011-x

3. Mangan PR, Harrington LE, O'Quinn DB, et al. Transforming growth factor-beta induces development of the $\mathrm{T}(\mathrm{H}) 17$ lineage. Nature. 2006;441(7090):231-234. doi:10.1038/nature04754

4. Veldhoen M, Hocking RJ, Atkins CJ, Locksley RM, Stockinger B. TGFbeta in the context of an inflammatory cytokine milieu supports de novo differentiation of IL-17-producing $\mathrm{T}$ cells. Immunity. 2006;24(2):179-189. doi:10.1016/j.immuni.2006.01.001

5. Nurieva R, Yang XO, Martinez G, et al. Essential autocrine regulation by IL-21 in the generation of inflammatory T cells. Nature. 2007;448(7152):480-483. doi:10.1038/nature05969

6. Milner JD, Brenchley JM, Laurence A, et al. Impaired T(H)17 cell differentiation in subjects with autosomal dominant hyper-IgE syndrome. Nature. 2008;452(7188):773-776. doi:10.1038/nature06764

7. Grimbacher B, Holland SM, Gallin JI, et al. Hyper-IgE syndrome with recurrent infections-an autosomal dominant multisystem disorder. $N$ Engl J Med. 1999;340(9):692-702. doi:10.1056/NEJM199903043400904

8. Chaimowitz NS, Branch J, Reyes A, et al. A novel STAT3 mutation in a qatari patient with hyper-IgE syndrome. Front Pediatr. 2019;7:130. doi:10.3389/fped.2019.00130

9. Papanastasiou AD, Mantagos S, Papanastasiou DA, Zarkadis IK. A novel mutation in the signal transducer and activator of transcription 3 (STAT3) gene, in hyper-IgE syndrome. Mol Immunol. 2010;47 (7-8):1629-1634. doi:10.1016/j.molimm.2010.01.010

10. Minegishi Y, Saito M, Nagasawa M, et al. Molecular explanation for the contradiction between systemic Th17 defect and localized bacterial infection in hyper-IgE syndrome. $J$ Exp Med. 2009;206 (6):1291-1301. doi:10.1084/jem.20082767

11. Woellner C, Gertz EM, Schaffer AA, et al. Mutations in STAT3 and diagnostic guidelines for hyper-IgE syndrome. J Allergy Clin Immunol. 2010;125(2):424-432.e8. doi:10.1016/j.jaci.2009.10.059

12. Deng Y, Li T, Xie X, et al. Hyper IgE syndrome associated with novel and recurrent STAT3 mutations: two case reports. Medicine (Baltimore). 2019;98(6):e14003. doi:10.1097/MD.0000000000014003

13. Hsu AP, Davis J, Puck JM, et al. STAT3 hyper IgE syndrome. In: Adam MP, Ardinger HH, Pagon RA, editors. Genereviews $\left({ }^{\circledR}\right)$. Seattle: University of Washington; 1993:1-19.

14. Grimbacher B, Schaffer AA, Holland SM, et al. Genetic linkage of hyper-IgE syndrome to chromosome 4. Am J Hum Genet. 1999;65 (3):735-744. doi: $10.1086 / 302547$

15. Foley JF. STAT3 regulates the generation of Th17 cells. $J$ Gen Physiol. 2007;17(380):677-685.

16. Myles IA, Anderson ED, Earland NJ, et al. TNF overproduction impairs epithelial staphylococcal response in hyper IgE syndrome. J Clin Invest. 2018;128(8):3595-3604. doi:10.1172/JCI121486

17. Sastalla I, Williams KW, Anderson ED, et al. Molecular typing of staphylococcus aureus isolated from patients with autosomal dominant hyper IgE syndrome. Pathogens. 2017;6(2):23. doi:10.3390/ pathogens6020023

18. Uto-Konomi A, Miyauchi K, Ozaki N, et al. Dysregulation of suppressor of cytokine signaling 3 in keratinocytes causes skin inflammation mediated by interleukin-20 receptor-related cytokines. PLoS One. 2012;7(7):e40343. doi:10.1371/journal.pone.0040343

19. Schimke LF, Sawalle-Belohradsky J, Roesler J, et al. Diagnostic approach to the hyper-IgE syndromes: immunologic and clinical key findings to differentiate hyper-IgE syndromes from atopic dermatitis. J Allergy Clin Immunol. 2010;126(3):611-617.e1. doi:10. 1016/j.jaci.2010.06.029 
20. Sowerwine KJ, Holland SM, Freeman AF. Hyper-IgE syndrome update. Ann N Y Acad Sci. 2012;1250(1):25-32. doi:10.1111/j.17496632.2011.06387.x

21. Vogel TP, Milner JD, Cooper MA. The ying and yang of STAT3 in human disease. J Clin Immunol. 2015;35(7):615-623. doi:10.1007/ s10875-015-0187-8
22. Erger RA, Casale TB. Interleukin-8 plays a significant role in IgE-mediated lung inflammation. Eur Respir J. 1998;11 (2):299-305. doi:10.1183/09031936.98.11020299

\section{Publish your work in this journal}

The Journal of Asthma and Allergy is an international, peer-reviewed open-access journal publishing original research, reports, editorials and commentaries on the following topics: Asthma; Pulmonary physiology; Asthma related clinical health; Clinical immunology and the immunological basis of disease; Pharmacological interventions and

Submit your manuscript here: https://www.dovepress.com/journal-of-asthma-and-allergy-journal new therapies. The manuscript management system is completely online and includes a very quick and fair peer-review system, which is all easy to use. Visit http://www.dovepress.com/testimonials.php to read real quotes from published authors. 